\title{
Aplicação de técnicas de processamento de dados GPR para delimitação de infiltração de água em vazamento de tubulação em via urbana \\ ${ }^{1}$ Maykon Masao Yano Taniyama, ${ }^{1}$ João Andrade dos Reis Júnior, ${ }^{2}$ Gildenilson Mendes Duarte, ${ }^{3}$ Diego da Costa Miranda \\ 1 - Universidade Federal Rural da Amazônia - UFRA - Campus Capanema \\ 2 - Universidade Federal Rural da Amazônia - UFRA - Campus Tomé-Açul \\ 3 - Universidade Federal do Pará - UFPA - Campus Belém
}

\section{Copyright 2019, SBGf - Sociedade Brasileira de Geofísica}

This paper was prepared for presentation during the $16^{\text {th }}$ International Congress of the Brazilian Geophysical Society held in Rio de Janeiro, Brazil, 19-22 August 2019.

Contents of this paper were reviewed by the Technical Committee of the $16^{\text {th }}$ International Congress of the Brazilian Geophysical Society and do not necessarily represent any position of the SBGf, its officers or members. Electronic reproduction or storage of any part of this paper for commercial purposes without the written consent of the Brazilian Geophysical Society is prohibited.

\begin{abstract}
Font: Arial Bold, 9)
In Brazil, a large portion of water waste is due to leaks in pipes along the distribution system. In the northern region, the waste reaches $47,3 \%$, which can generate a serious problem in the water supply of the population. Leaks from pipelines in public roads often cause major disturbances, and their identification in urban centers is greatly hampered by the impossibility of direct observation. We propose the use of the Ground Penetration Radar (GPR) method to identify and delineate leakage regions. To assess this problem, we used the GPR in an area with visible water leakage in the city of Capanema-PA, where it is expected changes in dielectric constant of the medium due to the infiltration of water. The acquired GPR radargrams show high-amplitude reflectors in the zone with water infiltration, which allowed the use of the energy attribute, as well as the use of the energy isosurfaces. Both techniques helped us to satisfactorily infer the approximate volume of leaked water and the extent of the affected area.
\end{abstract}

Keywords: GPR, Water Infiltration, Attribute of Energy, energy isosurfaces.

\section{INTRODUÇÃo}

O fornecimento de água potável é uma das grandes problemáticas mundiais atualmente, e sua escassez vem se acentuando seja devido à falta de investimento em novas fontes de água, de forma que supram as demandas cada vez maiores das populações dos grandes centros urbanos, seja pela perda de água nas redes de distribuições. A água um elemento vital para a sobrevivência de qualquer organismo vivo, assim como é fundamental para o funcionamento dos ecossistemas, comunidades e até mesmo para economia (ONUBR, 2010). De acordo com o Diagnóstico dos Serviços de água e Esgoto (2016), o Brasil desperdiça 38,1\%, de toda a água tratada, número 3,7\% superior ao ano de 2015. Grande parte dessa perda ocorre por vazamentos em tubulações ao longo das redes de distribuição de água, tal problema é inerente a qualquer sistema de abastecimento de água. Segundo ainda esse relatório, a região Norte é a que mais desperdiça, chegando a enormes 47,3\%.

Segundo a International Water Association, IWA (2002), a principal preocupação entre as companhias de saneamento são as perdas ao longo das redes de abastecimento. Logo, torna-se indispensável a utilização de novas tecnologias, que possibilitem dar suporte para tomadas de decisões, medidas mitigadoras, recuperação de danos, e, ainda, a redução de impactos potenciais presentes ou até mesmo futuros

A observação de tais vazamentos em subsuperfície nos centros urbanos é extremamente dificultada, devido à impossibilidade de observação direta, logo, grandes quantidades de metros cúbicos de água podem ser perdidas (TSUTIYA, 2004), provocando erosões de extensas áreas de subsolo, sem que esse problema possa ser percebido, e, por consequência, causando o eventual colapso das pavimentações.

Devido ao trânsito, o controle de vazamentos em tubulações nas vias públicas pode-se apontar como um entrave em detrimento à uma política de conservação e manutenção das vias, havendo carência de métodos de avaliação não destrutivos, rápidos, eficientes e de baixo custo, pois a maioria dos métodos usados em avaliações de pavimentos baseia-se em técnicas destrutivas, como furos de sondagem, ensaios de carga ou simuladores de tráfego, as quais oneram a análise (AMARAL, 2011).

Dessa forma, tais técnicas destrutivas apresentam-se pouco eficazes, necessitando-se, assim, de novas técnicas menos invasivas e de maior acurácia, como o uso do método geofísico Ground Penetration Radar (GPR), evitando que maiores prejuízos econômicos e ambientais ocorram, ou mesmo acidentes mais graves, como o ocorrido em Belém do Pará, onde uma cratera ocupou mais da metade da via colocando em risco motoristas e pedestres que passam pela Rua Ó de Almeida no dia $7 / 8 / 2017$, devido à um vazamento de água na tubulação que provocou o colapso da pavimentação (FOLHAPA, 2017).

Diversos autores têm utilizado o GPR para diversas aplicações, como na identificação de tubulações no subsolo (DIAS E FILHO, 2017), detecção de plumas de contaminação por hidrocarbonetos (SANTOS E GRIEP, 2008), mapeamento de vazamentos de óleo (OLIVEIRA, 2009), e até mesmo confirmando sua eficiência em áreas de testes controlados, denominados de "Sítio Controlado de Geofísica Rasa", onde simulam estudos de geofísica com o uso do GPR (RODRIGUES, 2004).

O objetivo deste trabalho foi desenvolver metodologias não invasivas de detecção de vazamentos 
urbana.

de água em subsuperfície em meios urbanos, envolvendo Física, Geofísica Rasa e Hidrogeologia. Tal conjunto de informações permitirá a detecção, delimitação e caracterização de áreas possivelmente erodidas em áreas alvo, em profundidade, com histórico de vazamento na cidade de Capanema, nordeste paraense (Figura 1), de tal forma que estas metodologias possam servir para a identificação de áreas que estejam com vazamentos, evitando-se, assim, maiores prejuízos, bem como acidentes mais graves.

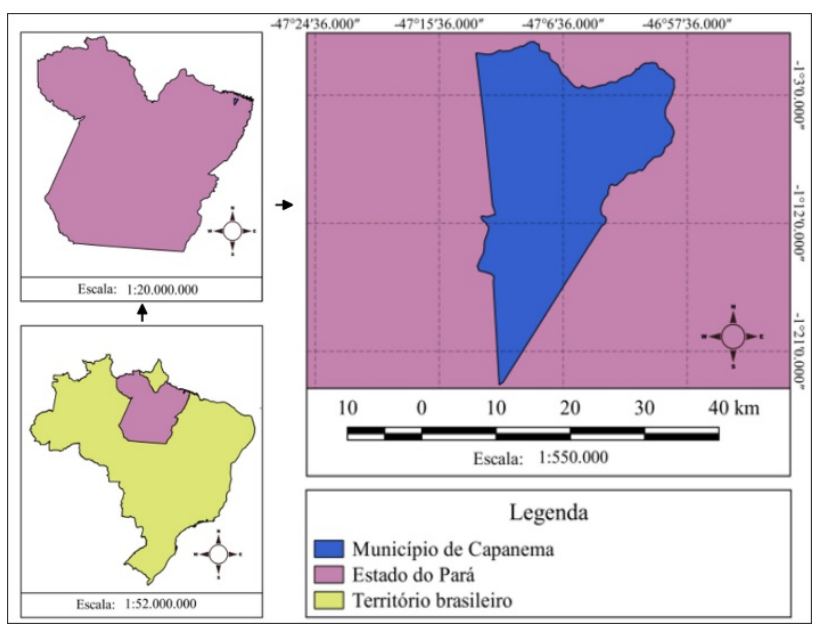

Figura 1 - Mapa de localização do município de Capanema - Pa. / Fonte: autor.

\section{METODOLOGIA}

O levantamento ocorreu na cidade de Capanema, na Travessa Leandro Pinheiro, próximo à Passagem São Raimundo (Figura 2). Na região estudada, ocorre uma camada de solo areno-argiloso amarelo avermelhada, entre as profundidades de 0 a 0,5 m. Abaixo desta camada ocorre uma outra de argila calcífera amarela, entre 0,5 a $8 \mathrm{~m}$. Nas profundidades de 8 a $17 \mathrm{~m}$ ocorre uma camada de areia calcífera cinza esbranquiçado, e logo abaixo uma camada de calcário cinza, entre 17 a 34 m (SIAGAS, 2017).

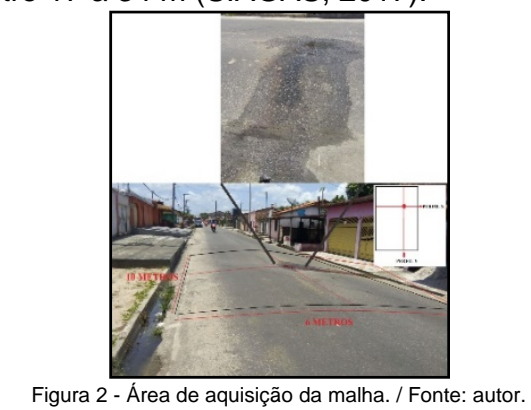

O perfil foi adquirido com afastamento constante entre as antenas (common off set), sobre uma área com vazamento visível e processo de erosão inicial. Foram realizados 34 perfis com espaçamento de 0,5 metros entre os perfis, dos quais 21 são perpendiculares à rua, denominados perfis $X$, possuindo 6 metros de comprimento, e outros 13 paralelos aos perfis $X$, denominados perfis $\mathrm{Y}$, possuindo 10 metros de comprimento, representados pela figura 1 , onde o ponto verde representa a posição $\mathrm{X}$ e $\mathrm{Y}$ a 0 metros, e o ponto azul representa o local de visível vazamento (Figura 3).

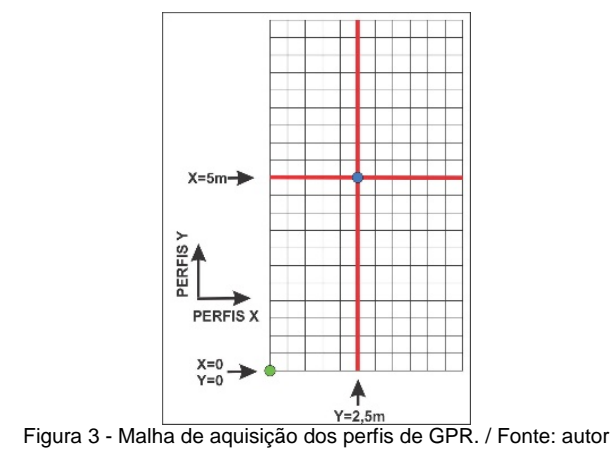

Para a aquisição dos dados foi utilizado o GPR com antena de $400 \mathrm{MHz}$, modelo SIS 3000 , e para a melhor distribuição dos traços, foi acoplada a antena um carrinho de antena com odômetro (Figura 4).

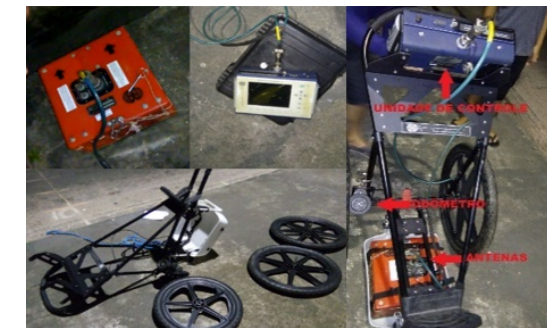

Figura 4 - Antenas, unidade de controle, carrinho e equipamento montado. / Fonte: autor.

O processamento dos dados de GPR objetivou buscar a melhor representação visual das respostas geofísicas para as feições estudadas, tendo como referência o perfil $X=5$ adquirido sobre a área de vazamento visível no asfalto. Para o processamento dos radargramas, foi utilizado o software Reflexw versão 8.5.2, tendo sido utilizado as seguinte etapas de processamento: remoção do tempo zero; atenuação de ruídos coerentes (background removal); remoção do ganho dado na aquisição; ganho energy decay; dewow; Fk filter; Fk migration; filtro passa-banda e conversão tempo/profundidade.

Uma comparação entre os dados GPR antes e depois da aplicação do processamento é apresentada no radargrama correspondente a linha $X=5$ (Figura 5). A seção GPR foi corrigida para o tempo zero, foram removidos as ondas diretas e ruídos de baixa e alta frequências. Foram corrigidos os efeitos relacionados à indução eletromagnética e atenuação do sinal com a profundidade, possibilitando visualizar de forma mais clara o limite em profundidade da região afetada pelo vazamento (refletores de maior amplitude). Por último, os refletores foram reposicionados com a conversão tempo em profundidade, tendo sido usado a velocidade de 0,113 $\mathrm{m} / \mathrm{ns}$, calculada através da hipérbole visualizada no perfil não migrado $Y=2,5 \mathrm{~m}$ (Figura 8). Após processados, os dados foram interpolados e convertidos para o formato SEG-Y, e posteriormente importados no software 
Opendtect para melhor visualização em ambiente virtual 3D e aplicação de atributos.

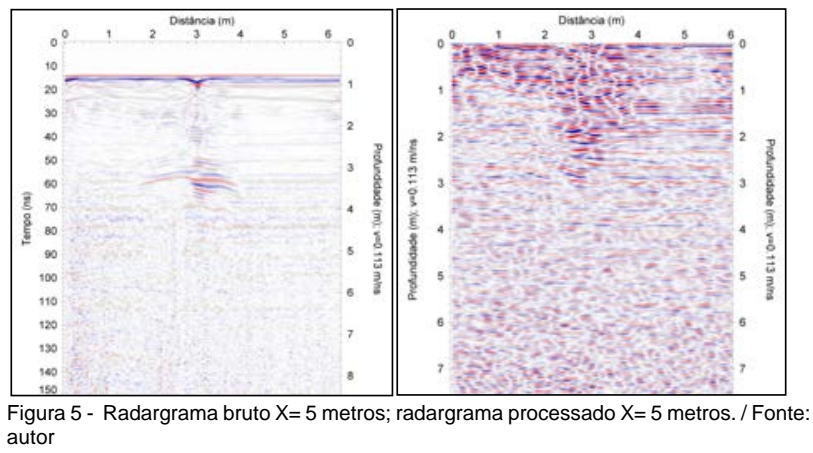

\section{RESULTADOS E DISCURSÃO}

Sabe-se que o método GPR identifica contrastes de impedância eletromagnética, e para meios de baixa perda, bem como para meios com baixa permeabilidade magnética, tais variações podem ser aproximadas como mudanças na constante dielétrica do subsolo. Em ambientes com infiltração de água no solo, como em vazamentos de tubulações, ocorre o aumento da constante dielétrica do meio, e, por conseguinte, aumento no contraste dessas áreas com o restante do solo.

Analisando os radargramas, visualiza-se regiões com refletores de altas amplitudes, tanto nos perfis $X$, quanto nos $\mathrm{Y}$, aqui apresentados por dois radargramas mais representativos de cada respectivo eixo, que cruzam entre si em cima do local de vazamento pontual (Figuras 6 e 7), isso ocorre devido a propagação das ondas EM, em meios de baixa perda, como o caso desta pesquisa, depender diretamente da constante dielétrica.

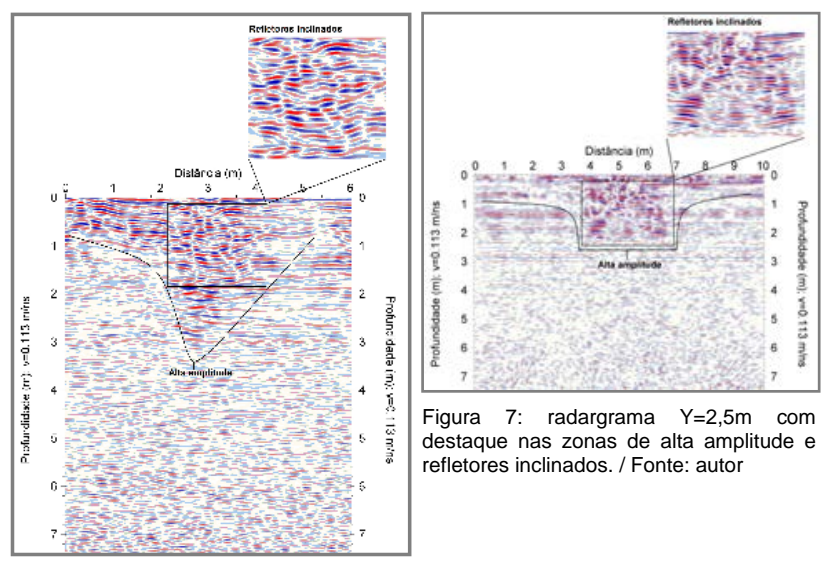

Figura 6: radargrama $X=5 \mathrm{~m}$ com destaque nas zonas de alta amplitude e refletores inclinados. / Fonte: autor

Na região onde ocorre o vazamento de água, os refletores apresentam-se levemente inclinados para baixo, como pode ser visualizado nas Figuras (6, 7 e 8).

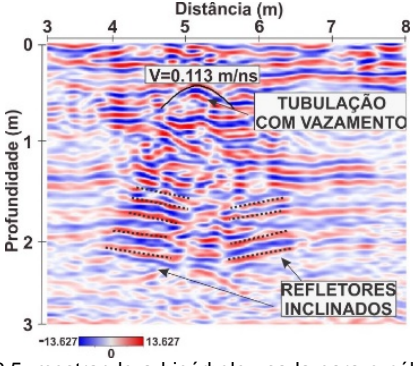

Figura 8 - Perfil $Y=2,5$, mostrando a hipérbole usada para o cálculo da velocidade. I Fonte: autor.

A onda EM propaga-se pela subsuperfície com velocidades que dependem do valor da constante dielétrica do meio, de acordo com a Equação 1. Desta forma, pode-se concluir que a onda EM, ao passar pela região de vazamento, tem sua velocidade diminuída, pois com a infiltração da água, ocorre aumento na constante dielétrica, e, por conseguinte, diminuição na velocidade da

$$
V=\frac{c}{\sqrt{\varepsilon_{0}}}
$$

onda EM, de acordo com a Equação 1.Desta forma, é perceptível, observando a Tabela 1, o elevado valor da constante dielétrica da água em relação ao ar, e a culminante capacidade de influenciar outros materiais, como é possível visualizar na abrupta elevação da constante dielétrica de um material geológico seco para um saturado. Esse fato confirma o comportamento das ondas EM na área de estudo, onde a área analisada, por ação antrópica de um vazamento na tubulação de água em área urbana, causou a infiltração de água no subsolo, saturando a subsuperfície no local, de tal modo que a área influenciada pela percolação da água pode ser visualizada e delimitada nos radargramas.

Tabela 1 - Constante dielétrica $\left(\varepsilon_{r}\right)$, velocidade $(v)$ e atenuação $(\alpha)$ de alguns materiais (modificada de DAVIS \& ANNAN (1989); ZENG \& MCMECHAN (1997)).

\begin{tabular}{|l|l|l|l|}
\hline Material & $\varepsilon_{r}$ & $\mathbf{v}(\mathbf{m} / \mathbf{n s})$ & $\alpha(\mathbf{d B} / \mathbf{m})$ \\
\hline Ar & 1 & 0,3 & 0 \\
\hline Água pura & 80 & 0,033 & 0,1 \\
\hline Água do mar & 80 & 0,01 & $10^{3}$ \\
\hline Areia seca & $3-5$ & 0,15 & 0,01 \\
\hline Areia saturada & $20-30$ & 0,06 & $0,03-0,3$ \\
\hline Solo argiloso saturado & 15 & $0,07-0,09$ & 21 \\
\hline Solo argiloso seco & 2.4 & 0,19 & 0,28 \\
\hline
\end{tabular}

Para uma melhor delimitação da área afetada pelo vazamento, todas as linhas $X \mathrm{e} Y$ foram interpoladas no Reflexw, e posteriormente inseridas no Opendtect.

Após essa etapa, foi aplicado o atributo GPR de Energia. Este atributo calcula a razão da soma dos quadrados das amplitudes pelo número de amostras da janela de tempo especificado para o cálculo, a qual deve ter o comprimento próximo ao período da frequência central do sinal. Com este atributo, é possível enfatizar refletores com baixas amplitudes e/ou irregulares, além de individualizar sequências com diferentes contrastes de impedância EM. Devido a estas características, este atributo foi aplicado na malha adquirida na área. 
A Figura 9a mostra uma perspectiva tridimensional das linhas $X=5 \mathrm{~m}$ e $\mathrm{Y}=2,5 \mathrm{~m}$, enquanto a Figura 9b mostra a timeslice de energia referente a $1 \mathrm{~m}$ de profundidade. Já a Figura 9c mostra uma junção dos radargramas $X=5$ e $Y=2,5$ com a timeslice de energia a 1 $\mathrm{m}$ de profundidade. Percebemos claramente a região de alta energia, correspondente a zona influenciada pelo vazamento (região com tonalidade amarela), ocasionado pelo aumento da constante dielétrica na zona de vazamento.

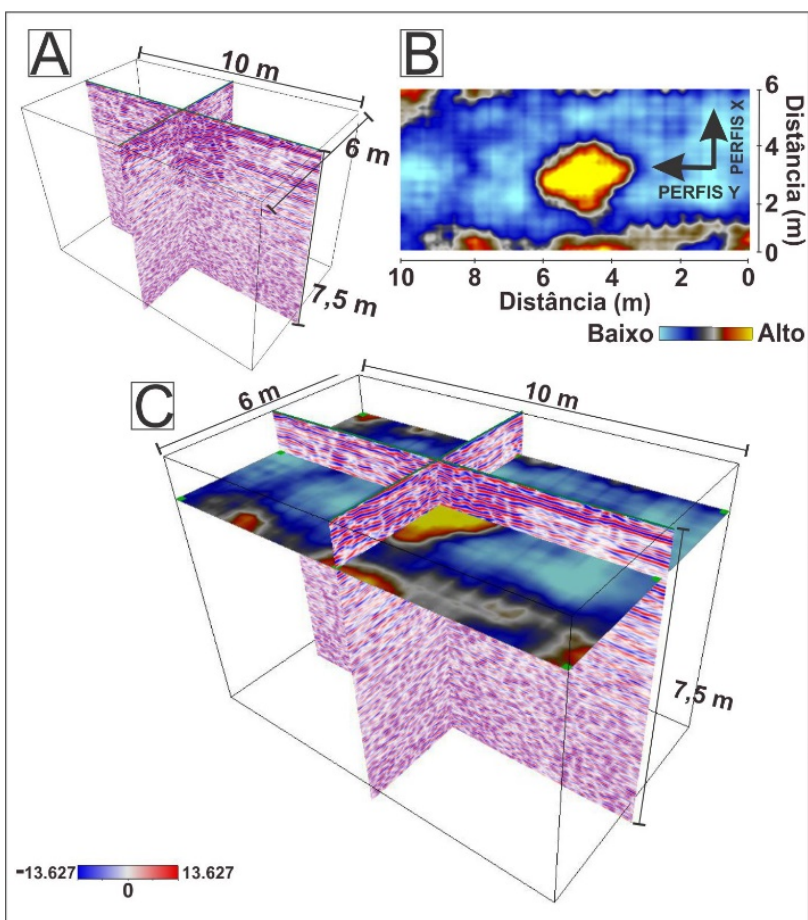

Figura 9 - A - Perfis $X=5 m$ e $Y=2,5 m$ cruzando a área de vazamento; $B$ - Timeslice de energia a $1 \mathrm{~m}$ de profundidade; $C$ - Perfis $X=5 \mathrm{~m}$ e $Y=2,5 \mathrm{~m}$ com a timeslice de energia, mostrando a relação entre os refletores de alta amplitude com a região de alta energia na timeslice de energia. / Fonte: autor.

Para uma melhor caracterização da geometria da área infiltrada, foi gerado um cubo de energia sobre a área de vazamento, e posteriormente criado uma Isosuperfície de Energia, possibilitando contornar a região infiltrada, bem como dimensionar o volume afetada pelo vazamento.

Como mostrado nas Figuras $10 \mathrm{a}$ e $10 \mathrm{~b}$, a área infiltrada apresenta um comprimento de $4 \mathrm{~m}$, e uma largura de $3,15 \mathrm{~m}$ na parte mais rasa, contudo tem sua área diminuída em profundidade. Já a Figura 10C, mostra a infiltração em profundidade, a qual chega aos $3 \mathrm{~m}$, mostrando que grande parte da água do vazamento tende a sair em superfície, devido, provavelmente, tanto pelo fato da tubulação está localizada a uma baixa profundidade, cerca de $0,5 \mathrm{~m}$ (Figura 8), bem como devido à alta pressão da água. Este fato é corroborado visualmente no local, onde é visível o escorrimento de água sobre o asfalto (Figura 2).

Com as dimensões coletadas, foi possível, ainda, estimar o volume da zona infiltrada, chegando a um valor aproximado de $20 \mathrm{~m}^{3}$. Este valor foi calculado no software Opendtect.

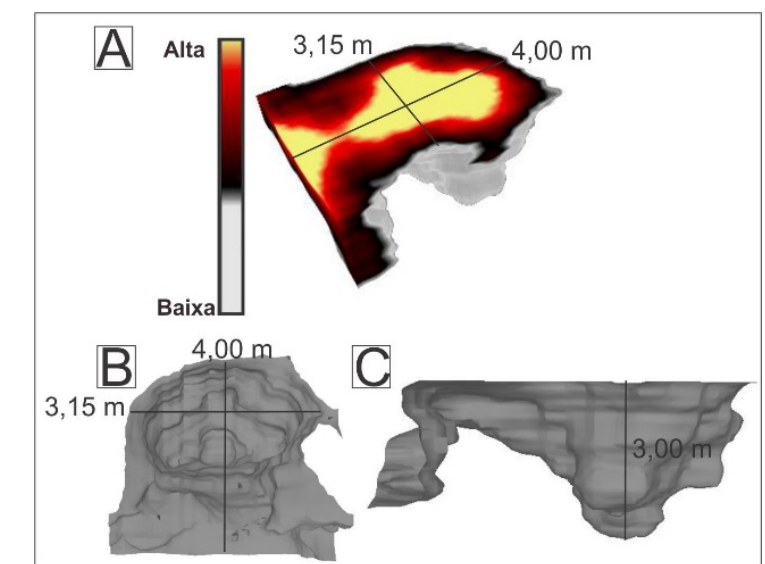

Figura 10 - A - Volume de Energia representado a área de infiltração; B - Visão Superior da Isosuperfície de Energia com dimensão superior; C - Visão lateral da Isosuperfície de Energia com dimensão inferior. / Fonte: autor.

É importante ressaltar, que através da análise dos dados não foi possível identificar áreas de erosão perceptível nos radargramas, levando a conclusão que o vazamento é recente. Porém, com a continuação desse processo, o fluxo da água em subsuperfície, poderá causar a erosão no local, que conforme (TOMINAGA; SANTORO; AMARAL, 2009) levará à formação de canais pela remoção de partículas, evoluindo no sentido contrário da água, podendo causar o colapso da área. Sendo de suma importância que o problema seja sanado o mais rápido possível, para que não ocorra como o caso de Harrisburg na Pensilvânia (dezembro de 2012), onde após vazamento de água em subsuperfície, houve erosão do subsolo e o colapso, formando uma enorme cratera (Figura 11).

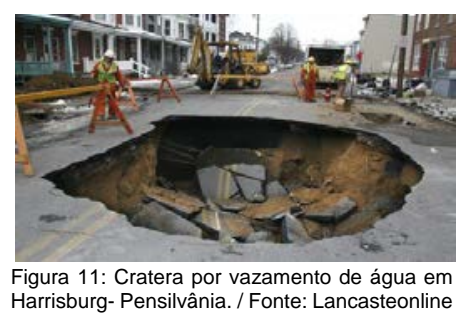

No Brasil ocorre diversos casos diariamente, como o ocorrido em João Pessoa, na Paraíba, onde, em outubro de 2018, um vazamento de água, erodiu e criou uma grande cratera em via pública (Figura 12).

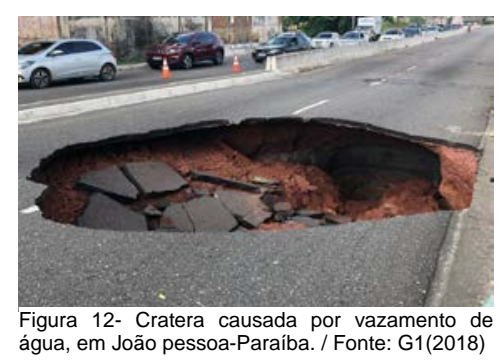

Os resultados encontrados nesta pesquisa, podem ser comparados aos alcançados nos experimentos 
controlados de Oliveira Jr. e Medeiros (2008), desenvolvido para investigar os fatores potencialmente responsáveis que influenciam na reflexão das ondas EM e na velocidade de propagação. Para tanto, os autores usaram amostras de areia, buscando as relações entre amplitudes das reflexões de GPR associadas, além de validar modelos empíricos conhecidos na literatura como o método indexado de refração complexa (CRIM) e a equação de Topp. O experimento consistiu em medir a variação da velocidade da onda de GPR em função do conteúdo de água em areia fina, adicionando água gradativamente. Após várias repetições, constatou-se o aumento da constante dielétrica e consequentemente a redução da velocidade da onda EM à medida que 0 conteúdo de água aumentava.

Tais relações obtidas por Oliveira Jr. e Medeiros (2008) são representadas através dos gráficos nas figuras 13 e 14, segundo os resultados obtidos nos experimentos, o mesmo autor obteve também um radargrama (Figura 15) ilustrando pontos de coleta, com características semelhantes aos obtidos nessa pesquisa, como regiões saturadas por água, áreas de alta amplitude e refletores inclinados.

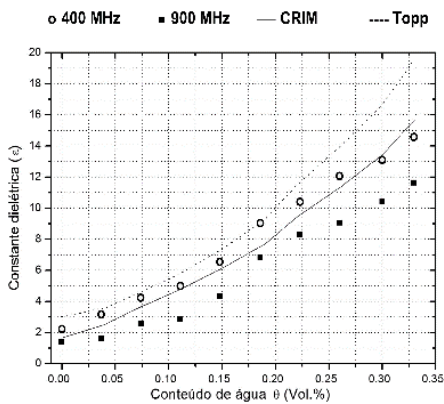

Figura 13: Constante dielétrica versus conteúdo de água. Os símbolos brancos indicam, medidas feitas com as antenas de $400 \mathrm{MHz}$ sobre diferentes amostras de areia, e os pontos pretos com antenas de $900 \mathrm{Mhz}$. As linhas contínua e pontilhada representam curvas empíricas associadas ao método Wyllie \& Gregory (1953) e a equação de Topp et al. (1980). / Fonte: Oliveira Jr. e Medeiros (2008)

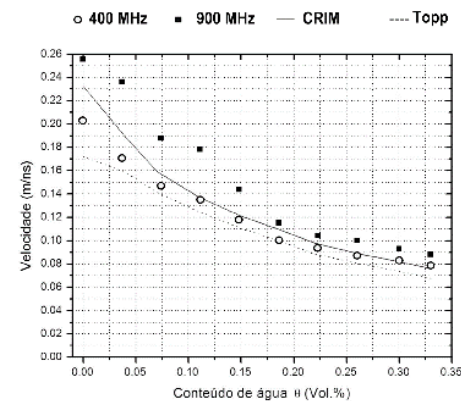

Figura 14: Velocidade versus conteúdo de água. Os símbolos brancos indicam medidas feitas com as antenas $400 \mathrm{MHz}$ sobre areia, e os pontos pretos com antenas de $900 \mathrm{Mhz}$. As linhas contínua e pontilhada representam curvas empíricas associadas ao método Wyllie \& Gregory (1953) e a equação de Topp et al. (1980). / Fonte: Oliveira Jr. e Medeiros (2008)

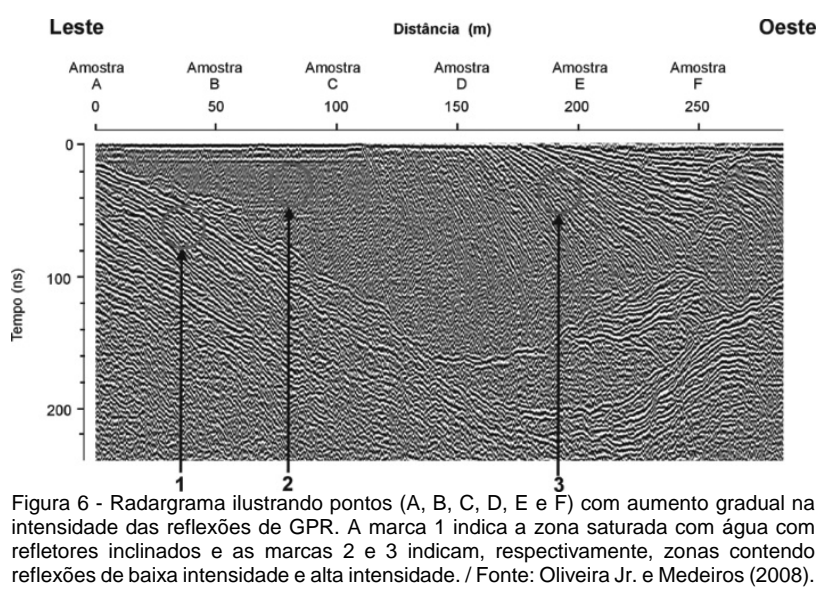

\section{Conclusão}

Os resultados mostraram regiões de altas amplitudes nos radargramas, em decorrência da percolação da água em subsolo, o que provoca grande aumento na constante dielétrica, possibilitando delimitar a área infiltrada. Através da aplicação do atributo GPR de Energia e de Isosuperfície de Energia, foi possível, ainda, delimitar o volume aproximado da área infiltrada, possibilitando interpretar que a infiltração é mais pronunciada em profundidades rasas, diminuindo em profundidade. Esse fato, ocorre, provavelmente em decorrência da baixa profundidade da tubulação, bem como da pressão da água na mesma, fazendo com que grande parte da água saia para a superfície. Esse fato, inclusive, é visualizado sobre o asfalto.

Foi possível, ainda localizar refletores inclinados, o que evidencia o processo inicial de infiltração no solo, contudo, não foi identificado área de erosão perceptível nos radargramas, levando a conclusão que o vazamento é recente, contudo, com a continuação desse processo, o fluxo da água em subsuperfície, poderá causar a erosão no local, através da formação de canais pela remoção de partículas, evoluindo no sentido contrário da água, podendo causar o colapso da área. Sendo de suma importância que o problema seja resolvido o mais rápido possível.

Vazamentos ao longo das redes de distribuição de água representam enormes perdas em diversos âmbitos, sociais, ambientais e econômicos, provocando, como consequências, a elevação no custo de produção, devido gastos com energia elétrica, produtos químicos em tratamentos, risco de contaminação, além de interrupções no abastecimento, e, desta forma, a metodologia aqui apresentada poderá ser aplicada com o intuito de amenizar esses prejuízos.

\section{Agradecimentos}

Os autores agradecem a UFPA pela disponibilização do equipamento, e ao CNPQ pela bolsa recebida pelo aluno Maykon Masao Yano Taniyama. 
Aplicação de técnicas de processamento de dados GPR para delimitação de infiltração de água em vazamento de tubulação em via urbana.

\section{REFERÊNCIAS}

AMARAL, C.N. M. Investigação de pavimento asfáltico por meio do método geofísico radar de penetração do solo. 2011. 50 f. Dissertação (Mestrado em Geofísica) Universidade Federal do Pará, Belém, 2011.

CRATERA coloca motoristas e pedestres em risco no bairro da Campina, em Belém. Disponível em: $<$ http://www.folhapa.com.br/artigo/204771/Crateracoloca-motoristas-e-pedestres-em-risco-no-bairro-daCampina--em-Belem>. Acesso em: maio 2018.

DAVIS, J. L; ANNAN, A. P. GROUND-PENETRATING RADAR FOR HIGH-RESOLUTION MAPPING OF SOIL AND ROCK STRATIGRAPHY 1. Geophysical prospecting, v. 37, n. 5, p. 531-551, 1989.

DO NASCIMENTO DIAS, Gleide Alencar; TEXEIRA FILHO, Paulo César. Detecção de Tubulações Através do Método Radar de Penetração no Solo (GPR) na Cidade Universitária-Illha do Fundão, Brasil. Anuário do Instituto de Geociências, 2017, 40.1.

INTERNATIONAL WATER ASSOCIATION. IWA. Water Management - Industry as a Partner for Sustainable Development. IWA, UNEP, United Kingdom, 60 p. 2002.

LANCASTER ONLINE. Massive sinkholes collapse Harrisburg roadway. Disponível em:< https://lancasteronline.com/news/massive-sinkholescollapse-harrisburg-roadway/article_4aa0aee5-87c2527d-a223-5ce8bd96bd06.html> Acesso em: janeiro de 2019.

MINISTÉRIO DAS CIDADES. Secretaria Nacional de Saneamento ambiental. Diagnóstico dos Serviços de Água e Esgotos. Brasília, 2018. 220 p. Disponível em: <http://www.snis.gov.br/downloads/diagnosticos/ae/2016/ Diagnostico_AE2016_Retificado.zip>. Acesso em: maio 2018.

$\begin{aligned} & \text { NAÇÕES UNIDAS NO BRASIL. A ONU e a } \\ & \text { água. } \\ & \text { <isponível }\end{aligned}$
$\begin{aligned} & \text { <https://nacoesunidas.org/acao/agua/>. Acesso em: } \\ & \text { em: }\end{aligned}$ maio 2018.

OLIVEIRA JR, Josibel Gomes de; MEDEIROS, Walter Eugênio de. Influência do conteúdo de água, granulometria e minerais pesados sobre as reflexões de GPR em corpos arenosos inconsolldados. Revista Brasileira de Geofísica, 2008, 26.4: 437-449.

OLIVEIRA, Maria Gileide de. O uso do método GPR para mapear interferências no subsolo urbano e diagnosticar a contaminação ambiental de vazamentos de óleo em cabos elétricos subterrâneos. Revista Brasileira de Geofísica, 2009, 27.2: 297-297.
Rauen, V. A. B. (2014). Análise espacial de vulnerabilidade a vazamentos em rede de abastecimento de água (Doctoral dissertation, Universidade de São Paulo).

RODRIGUES, Selma Isabel. Caracterização GPR de Tambores Metálicos e Plásticos: Estudo sobre o Sítio Controlado do IAG/USP. 2004. PhD Thesis. Universidade de São Paulo.

SANTOS, Aline Rêgo. DETECÇÃO DE PLUMAS DE CONTAMINAÇÃO POR HIDROCARBONETOS NO SUBSOLO ATRAVÉS DO MÉTODO RADAR DE PENETRAÇÃO DO SOLO (GPR). 2008. PhD Thesis. Universidade Federal do Rio Grande.

TOMINAGA, L. K.; SANTORO, J.; AMARAL, R. Desastres Naturais: Conhecer para prevenir. São Paulo: Instituto Geológico. 196 p. 2009.

TOPP GC, DAVIES JL \& ANNAN AP. 1980. Electromagnetic determination of soil water content: measurements in coaxial transmission lines. Water Resources Research, 16: 574-582.

TSUTIYA, M.T. Abastecimento de água. São Paulo: Departamento de Engenharia Hidraulica e Saneamento da Escola Politécnica da Universidade de São Paulo, 2004.

VAZAMENTO de água abre grande buraco em rua de João Pessoa e interdita trânsito. Disponível em: < https://g1.globo.com/pb/paraiba/noticia/2018/10/23/vazam ento-de-agua-abre-grande-buraco-em-rua-de-joao-

pessoa-e-interdita-transito.ghtml >. Acesso em: janeiro 2019.

SIAGAS. Sistema online de informação de água subterrânea. Disponível em: <http://siagasweb.cprm.gov.br/layout/> acesso em: $10 \mathrm{de}$ março de 2019.

WYLLIE MRJ \& GREGORY AR. 1953. Formation factors of unconsolidated porous media: influence of particle shape and effect of cementation. Petroleum Transactions AIME, 198: 103-110.

ZENG, Xiaoxian; MCMECHAN, George A. GPR characterization of buried tanks and pipes. Geophysics, v. 62, n. 3, p. 797-806, 1997. 